\section{Melancholia and the probability and lethality of suicide attempts}

\author{
MICHAEL F. GRUNEBAUM, HANGA C. GALFALVY, MARIA A. OQUENDO, \\ AINSLEY K. BURKE and J. JOHN MANN
}

\begin{abstract}
Summary We compared suicide attempts associated with melancholic $v$. non-melancholic major depression in 377 patients. Controlling for depression severity and other covariates, melancholia at baseline assessment was associated with more serious past suicide attempts and with the probability of suicide attempt during follow-up.
\end{abstract}

\section{Declaration of interest None.}

Major depression is the psychiatric disorder most frequently associated with suicide (Barraclough et al, 1974; Henriksson et al, 1993). We predicted that melancholia would be associated with increased probability and lethality of suicide attempts.

\section{METHOD}

This study included 377 patients consecutively enrolled in depression protocols at two university hospitals. Physical and laboratory examinations excluded neurological or medical conditions and illicit substance use. The sample had a mean age of 40.1 years (s.d. $=13.3$, range $18-81$ ) and was $69 \%$ female, $71 \%$ White, $31 \%$ married; $55 \%$ were in-patients. Half $(n=192)$ reported a history of a suicide attempt (mean 2.6 lifetime attempts, s.d.=2.3), defined as a self-destructive act with intent to die. At baseline, 151 (40\%) met DSMIII-R (American Psychiatric Association, 1987) or DSM-IV (American Psychiatric Association, 1994) criteria for melancholia and 226 did not. A total of 263 participants received follow-up assessments for up to 2 years. Participants gave written informed consent, as approved by the Institutional Review Boards.

Consensus Axis I and II diagnoses were made based on the Structured Clinical Interview for DSM-III-R/DSM-IV, patient edition (SCID-I/II; Spitzer et al, 1990; First et al, 1996). Study scales were: the 17-item Hamilton Rating Scale for Depression (HRSD; Hamilton, 1960), the Beck Depression Inventory (BDI; Beck et al, 1961); the Beck Hopelessness Scale (Beck et al, 1974); the Reasons for Living Inventory (Linehan et al, 1983); the Columbia Suicide History Form (Oquendo et al, 2003); the Brown-Goodwin Aggression Inventory (Brown et al, 1979); the Buss-Durkee Hostility Inventory (Buss \& Durkee, 1957); the Barratt Impulsivity Scale (Barratt, 1965); the Scale for Suicidal Ideation (Beck et al, 1979); and the Suicide Intent Scale (Beck et al, 1975). The seriousness of suicide attempts was rated by consensus with the Medical Lethality Scale (MLS; Beck et al, 1975), scored 0-8 (0, no medical harm; 8, death; intraclass coefficient 0.94$)$. Interrater agreement and intraclass coefficients were good to excellent (Mann et al, 1999).

The melancholia and non-melancholia subgroups were compared using $t$-tests, Wilcoxon tests, or the $\chi^{2}$ statistic, as appropriate. We used the Bonferroni correction for multiple tests. Significant variables were analysed with multivariable regression methods.

\section{RESULTS}

After Bonferroni correction for 25 tests, we found that patients in the melancholia group were older at the onset of their depressive illness $(t=-3.88$, d.f. $=358 ; P<0.001)$ and at the study baseline assessment $(t=-3.61$, d.f. $=374 ; P<0.001)$. They were more likely to be married $\left(\chi^{2}=9.69\right.$, d.f. $\left.=1 ; P=0.0018\right)$ and were more depressed as measured by baseline HRSD score $(t=-7.55$, d.f. $=370$; $P<0.001)$. The groups did not differ in comparisons of gender, race, number of prior depressive episodes, length of index episode, rate of bipolarity, Cluster B personality disorder or substance misuse comorbidity, history of smoking or past medical problems, age at first psychiatric hospitalisation, number of hospitalisations, frequency of psychotic features, baseline BDI score, suicidal ideation, impulsivity, aggression, hostility, hopelessness, reasons for living, probability of a past suicide attempt or number of attempts by firstdegree relatives.

We compared the melancholia $(n=73)$ and non-melancholia $(n=119)$ patients who had a history of at least one suicide attempt. After Bonferroni correction for seven tests, we found that those with melancholia had made more serious past suicide attempts $(t=-3.17, \quad$ d.f. $=186$; $P=0.0018$ ). There were no differences in age at the first or at the most serious past attempts, or in time between first depressive episode and first suicide attempt, number of past attempts, or suicide intent score.

\section{Regression analysis}

We performed an ordinal regression with the maximum lethality score of past suicide attempts as the dependent variable. The independent variables were presence of melancholia, age, HRSD score, marital status and age at first major depressive episode. Only melancholia was associated with past suicide attempt lethality score (OR 2.2, 95\% CI 1.3-3.8; $P=0.003$ ).

Of the 263 participants for whom follow-up data were obtained, 43 (16\%) had made a suicide attempt during followup; 4 of them died. A Cox proportional hazards survival analysis with time to first attempt as the dependent variable and the same independent variables as above showed that only melancholia predicted suicide attempt during follow-up (hazard ratio $2.8,95 \%$ CI 1.4-5.3; $P=0.002$ ).

In a censored regression with the maximum lethality score of suicide attempts during follow-up as the dependent variable and the same independent variables as above, only HRSD score was associated with the lethality score of follow-up attempts (estimate $0.09 ; P=0.04$ ). Three of the four persons who killed themselves during the follow-up period had melancholia at the baseline assessment.

Regression analyses with the eight features of DSM-IV melancholia as dichotomous independent variables (present $v$. subthreshold or absent on SCID) and suicide attempt lethality or probability as dependent variables showed, after Bonferroni correction for eight tests, that only early morning awakening was associated with the maximum lethality score of past 
attempts (OR 2.4; $P=0.005)$. No feature was associated with lethality prospectively or with suicide attempt probability retrospectively or prospectively.

Using ordinal logistic regression, adjusting for baseline age, HRSD score, marital status and age at first major depression, the number of melancholic features was associated with past lethality (OR $1.17 ; P=0.03)$. With each additional melancholic feature, past lethality score increased by $17 \%$. Age was also significant (OR 1.03; $P=0.03$ ).

Using proportional hazards regression and adjusting for the same independent variables, the total number of melancholic features was associated with future attempt probability (hazard ratio $1.24 ; P=0.007$ ).

\section{DISCUSSION}

Melancholia at baseline is associated with more serious past suicide attempts and with the probability of future attempts, independent of depression severity. On average, those without melancholia did not require hospitalisation for the medical management of their suicide attempts; those with melancholia did.

Baseline HRSD score predicted greater lethality of future suicide attempts. Melancholia did not predict lethality prospectively, perhaps owing to a lack of statistical power. Global depression severity, as measured by the HRSD and BDI, is not consistently associated with suicide attempt lethality (Malone et al, 1996). Defining depressive features that confer a higher risk of suicide - such as melancholia - may help in the treatment of people who may be suicidal.

People with melancholic depressive disorder, as defined by the Clinical Outcomes in Routine Evaluation scale of psychomotor disturbance (Parker et al, 1994) and the Newcastle endogeneity scale (Carney et al, 1965), are reported to be more cognitively impaired than those with non-melancholic depression, suggesting an anterior cingulate abnormality that could diminish cognitive flexibility and influence decision-making (Austin et al, 1999). This might increase the risk of more serious suicide attempts and represents an area for future inquiry.

A limitation of this study is that we defined the melancholia group on the basis of an index episode. Studies suggest stability (Paykel et al, 1976; Kendler et al, 1996) and instability (Oquendo et al, 2004) of depressive symptoms across

MICHAEL F. GRUNEBAUM, MD, HANGA C. GALFALVY, PhD, MARIA A. OQUENDO, MD, AINSLEY K. BURKE, PhD, J. JOHN MANN, MD, Department of Neuroscience, New York State Psychiatric Institute and Columbia University, New York, New York, USA

Correspondence: Dr Michael F. Grunebaum, Department of Neuroscience, New York State Psychiatric Institute, I05I Riverside Drive, Box 42, New York, NY 10032, USA. Tel: 212543 5842; fax: 212543 6017; e-mail: mfgl4@columbia.edu

(First received 6 June 2003, final revision 5 December 2003, accepted 6 January 2004)

episodes. The non-melancholia group included some people with sub-syndromal melancholic symptoms, which would have diminished our findings. Lethality scores for past suicide attempts were obtained at baseline, primarily by self-report. Raters were not masked to depressive subtype but were unaware of the hypothesis. Follow-up data could not be obtained for 114 participants; however, they did not differ from participants who were followed up on any variable in the prospective regression model.

\section{ACKNOWLEDGEMENTS}

David A. Brent MD contributed to data collection and made helpful comments on the manuscript. Clinical ratings were completed by members of the Clinical Evaluation Core of the Conte Neuroscience Center. The study was supported by PHS grants $\mathrm{MH} 46745, \mathrm{MH} 48514$ and MH62l85 (Conte Neuroscience Center).

\section{REFERENCES}

American Psychiatric Association (1987) Diagnostic and Statistical Manual of Mental Disorders (3rd edn, revised) (DSM-III-R). Washington, DC: APA.

American Psychiatric Association (1994) Diagnostic and Statistical Manual of Mental Disorders (4th edn) (DSM-IV). Washington, DC: APA.

Austin, M.-P., Mitchell, P., Wilhelm, K., et al (1999) Cognitive function in depression: a distinct pattern of frontal impairment in melancholia? Psychological Medicine, 29, 73-85.

Barraclough, B., Bunch, J., Nelson, B., et al (1974) A hundred cases of suicide: clinical aspects. British Journal of Psychiatry, 125, 355-373.

Barratt, E. S. (1965) Factor analysis of some psychometric measures of impulsiveness and anxiety. Psychological Reports, 16, 547-554.

Beck, A. T., Ward, C. H., Mendelson, M., et al (1961) An inventory for measuring depression. Archives of General Psychiatry, 4, 53-63.

Beck, A. T., Weissman, A., Lester, D., et al (1974) The measurement of pessimism: the hopelessness scale. Journal of Consulting and Clinical Psychology, 42, 86I-865.

\section{Beck, A.T., Beck, R. \& Kovacs, M. (1975)}

Classification of suicidal behaviors: I. Quantifying intent and medical lethality. American Journal of Psychiatry, 132 , 285-287.

Beck, A. T., Kovacs, M. \& Weissman, A. (1979)

Assessment of suicidal intention: the scale for suicide ideation. Journal of Consulting and Clinical Psychology, 47, 343-352.

Brown, G. L., Goodwin, F. K., Ballenger, J. C., et al (1979) Aggression in human correlates with cerebrospinal fluid amine metabolites. Psychiatry Research, I, |3|-139.

Buss, A. H. \& Durkee, A. (1957) An inventory for assessing different kinds of hostility. Journal of Consulting Psychology, 2I, 343-349.

Carney, M. W. P., Roth, M. \& Garside, R. F. (1965) The diagnosis of depressive syndromes and the prediction of ECT response. British Journal of Psychiatry, 3, 659-674.

First, M. B., Spitzer, R. L., Gibbon, M., et al (1996) Structured Clinical Interview for DSM-IV Axis II Personality Disorders (SCID-II), Version 2.0. New York: Biometrics Research Department, New York State Psychiatric Institute.

Hamilton, M. (1960) A rating scale for depression. Journal of Neurology, Neurosurgery and Psychiatry, 23, 56-62.

Henriksson, M. M., Aro, H. M., Marttunen, M. J., et al (1993) Mental disorders and comorbidity in suicide. American Journal of Psychiatry, 150, 935-940.

Kendler, K. S., Eaves, L. J., Walters, E. E., et al (1996) The identification and validation of distinct depressive syndromes in a population-based sample of female twins. Archives of General Psychiatry, 53, 391-399. Linehan, M. M., Goodstein, J. L., Nielsen, S., et al (1983) Reasons for staying alive when you are thinking of killing yourself: the reasons for living inventory. Journal of Consulting and Clinical Psychology, 5I, 276-286.

Malone, K. M., Corbitt, E. M., Li, S., et al (1996)

Prolactin response to fenfluramine and suicide attempt lethality in major depression. British Journal of Psychiatry, 168, 324-329.

Mann, J. J., Waternaux, C., Haas, G. L., et al (1999) Towards a clinical model of suicidal behavior in psychiatric patients. American Journal of Psychiatry, 156 181-189.

Oquendo, M. A., Halberstam, B. \& Mann, J. J. (2003) Risk factors for suicidal behavior: utility and limitations of research instruments. In Standardized Evaluation in Clinical Practice (ed. M. B. First), pp. 103-130.Washington, DC: American Psychiatric Publishing.

Oquendo, M. A., Barrera, A., Ellis, S. P., et al (2004) Instability of symptoms in recurrent major depression: a prospective study. American Journal of Psychiatry, in press.

Parker, G., Hadzi-Pavlovic, D., Wilhelm, K., et al (1994) Defining melancholia: properties of a refined sign-based measure. British Journal of Psychiatry, I64, 316-326.

Paykel, E. S., Prusoff, B. A. \& Tanner, J. (1976) Temporal stability of symptom patterns in depression. British Journal of Psychiatry, 128, 369-374.

Spitzer, R. L., Williams, J. B.W., Gibbon, M., et al (1990) Structured Clinical Interview for DSM-III-R Patient edition (SCID-P). Washington, DC: American Psychiatric Press. 